\title{
A NOTE ON HAUSA PLURALS
}

\author{
Donald A. Burquest \\ University of Texas at Arlington
}

\begin{abstract}
In their presentation of three-dimensional phonology, Halle and Vergnaud [1980, 1981] propose that Hausa singular nouns are morphologically complex like the plural forms, composed of a stem plus a singular suffix. This paper argues that this analysis is incorrect, but that the proposal that singular nouns are morphologically complex is not necessary to demonstrate the usefulness of an autosegmental analysis. Among the arguments presented is a claim that palatalization of coronal obstruents in Hausa is a cyclic rule, but one applying only to derived words, not stems. It is further demonstrated that Hausa makes use of rules which in parallel fashion delete syllable nuclei $o c-$ curring directly preceding syllable nuclei, and syllable appendices occurring directly preceding syllable appendices. Thus, the two approaches of autosegmental phonology and lexical phonology work together to account for the facts of the Hausa nominal forms in question.
\end{abstract}

Halle and Vergnaud [1980, 1981] propose an autosegmental analysis of Hausa noun plurals in which the stem and suffix are treated as being on separate tiers, following a form of representation originally proposed in McCarthy [1979] and repeated in McCarthy [1981]. Pluralization in Hausa is relatively complex, but a number of patterns are treated insightfully within their approach. Among the types of pluralization discussed are the following (as with the Halle and Vergnaud articles, there is no attempt to treat tone here):

(1)

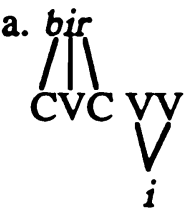

bir $+i i$ b.

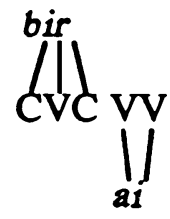

bir $+a i$ 'monkeys' 
(2)

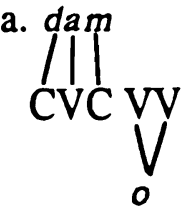

dam +oo 'land monitor' b.

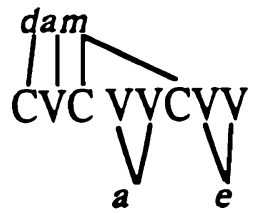

(3)

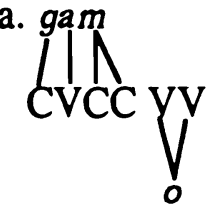

b.

dam +aamee 'land monitors'

$$
\text { gamm too 'headpad' }
$$

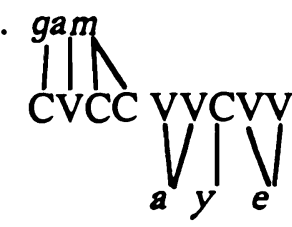

$$
\text { gamm +aayee 'headpads' }
$$

b.

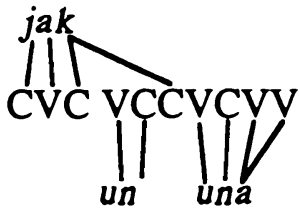

$j a k+a a$

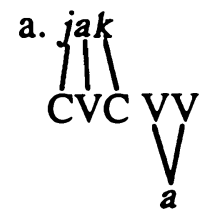

'bag' jak +unkunaa 'bags'

In (1) an apparent case of simple suffixation in the plural is seen. The other examples are more complex (and still more complex patterns are discussed in their paper), but the principle of the analysis is clear: the stem and affixes are functioning on different tiers and are mapped independently onto the appropriate CV template. In partially reduplicated plurals like (2) and (4), potential crossing of association lines (prohibited by the Well-Formedness Condition in all of its stated forms) can be avoided by this formalism, and the generalization of copying of the final stem consonant can be neatly captured. It should be noted that in certain definable contexts (Halle and Vergnaud refer to Newman [1972] for a definition of such contexts) the final consonant is not copied, but the segment $y$ is inserted (probably by default assignment) in the vacant $C$ slot instead, as in (3).

The analysis is an inviting one because of its simplicity. However, it is not clear that the basic singular form is in fact a construction composed of a stem plus affix. If it is not, the configuration in the singular examples in (a) above is incorrect, and as a consequence, the configuration in the plural examples in (b) is threatened as well. Three arguments bear on the question.

First, such a singular affix as the $i, 00$, and a in the (a) examples has questionable status as a morpheme because it lacks the two normal characteristics of morphemes-specifiable shape and productive meaning. Note that the shape of 
the final vowel of noun singular forms is quite variable, including at least the following:

$\begin{array}{lll}\text { (5) ii } & \text { daajii } & \text { 'the bush' } \\ \text { ee } & \text { karee } & \text { 'dog' } \\ \text { aa } & \text { daawaa } & \text { 'guinea corn' } \\ \text { oo } & \text { bangoo } & \text { 'wall' } \\ \text { uu } & \text { hannuu } & \text { 'arm' } \\ \text { ai } & \text { kai } & \text { 'head' }\end{array}$

It should be noted that these particular forms represent the entire inventory of long vowels in Hausa (plus one of the two diphthongs). It may be possible to state a generalization to predict the specific final vowel of noun singulars in particular cases, but such a pattern does not immediately suggest itself. To some extent there is a generalization which can be based on gender, viz., that nouns which are grammatically feminine in gender (distinguished from so-called masculine nouns by patterns of agreement and suffixation in specific constructions) commonly end in -aa. The following can be presented as examples:

(6)

$\begin{array}{ll}\text { Kafaa } & \text { 'foot' } \\ \text { kyanwaa } & \text { 'cat' } \\ \text { ciyaawaa } & \text { 'grass' }\end{array}$

By contrast, masculine nouns commonly end in a vowel other than -aa (with the exception of daawaa all the examples in (5) are masculine), but examples of masculine nouns ending in the pattern -aa are not hard to find:

(7)

$\begin{array}{ll}\text { gidaa } & \text { 'compound' } \\ \text { baayaa } & \text { 'back' } \\ \text { gabaa } & \text { 'front' } \\ \text { daa } & \text { 'son' } \\ \text { dawaa } & \text { 'the bush' }\end{array}$

It appears to be the case, then, that the precise nature of the final vowel of the singular form of nouns is not predictable, which means that under the Halle and Vergnaud analysis each noun will need to be specified for the singular marker with which it occurs.

But even if the singular forms could be treated as constructions of stem plus suffix, this approach is not helpful as regards the plural forms, because even though there are some predictable patterns for pluralization, to a significant ex- 
tent there is apparent arbitrariness. 1 Note the variation in the singular forms of the following sets of nouns, all of which within the same set manifest the same pattern of pluralization:

$$
\text { Singular Plural }
$$

a. jaakii harshee

riigaa

kwandoo

rumbuu

b. fiilii

wukaa

zoomoo

tsuntsuu jaakunaa

harsunaa

riigunaa

kwandunaa

rumbunaa

fiilaayee

wukaakee

zoomaayee

tsuntsaayee 'donkey'
'tongue'
'gown'
'basket'
'granary'

'field'

'knife'

'hare'

'bird'

Given such variation, it is clear that the plural class of the noun must either be lexically specified in at least some instances, e.g. for (a) vs (b) in (8), or determined by a set of rules which take tone and the final vowel of the singular into account. If in addition the singular class itself must be specified lexically in any case (so as to account for the specific singular suffix it occurs with as required by the Halle and Vergnaud analysis), it can be seen that there is no gain in simplicity by separating the final vowel of the singular as a suffix. Because its precise nature must still be specified in each case, unless there is strong evidence to the contrary it might just as well be left attached and treated as part of the stem itself.

The situation is not improved even if a more liberal interpretation of the morpheme concept is proposed. For example, Aronoff [1976] cites forms such as English mit (as in remit, commit, transmit, etc.) and proposes that the traditional definition of a morpheme as "an arbitrary constant union of sound and meaning"

${ }^{1}$ Russ Schuh has pointed out to me that if tone and final vowel are taken into account, prediction of the plural form is possible. However, there are a number of cases in which a given noun has alternative forms, among them the following:

$\begin{array}{lll}\text { abookii } & \text { abookai/abookanai } & \text { 'friend' } \\ \text { akuya } & \text { awaakii/awaakai } & \text { 'goat' } \\ \text { alaamaa } & \text { alaamuu/alaamoomii } & \text { 'sign' } \\ \text { jaakii } & \text { jaakunaa/jaakai } & \text { 'donkey' }\end{array}$

Such variations make a rule accounting for plural forms difficult, but even if one is possible, such regularities as exist are dependent upon the identity of the final vowel of the singular form, and as I am arguing, there is nothing to be gained by treating the final vowel as a suffix. As I will discuss below, there is a more insightful treatment available anyway. 
(p. 15) be modified. He points out that mit must be considered a morpheme, because it consistently is subject to the same phonological process in words such as remission, commission, transmission. Thus, even through there is no constant of meaning, there is a constant of phonological patterning, and he suggests that the definition of morpheme be broadened to recognize such phenomena.

It might be suggested that the Hausa forms cited above can be viewed in this way as well, that the final vowels of the singular forms can be considered a morpheme even though they lack consistent patterning of form and meaning. Hausa nouns, however, show nothing of the sort of phonological consistency shown by English mit. Further, the only phonological pattern holding among the singular forms that would allow recognition of the final vowel as being varied instances of the same unit is that the "singular morpheme" proposed by Halle and Vergnaud is associated with a VV portion of the CV template, i.e. it is a long vowel. However, it seems unlikely that the major class features distinguishing $\mathrm{C}$ and $\mathrm{V}$ would serve in any language as a specific morpheme, and there is no evidence that this is the case in Hausa (for example, note the long vowels in other than final position in the examples above). In addition, there are numerous examples of singular nouns which are not VV finally, e.g. aniini 'tenth of a penny', maage 'cat', faada 'palace', goor̃o 'kola', aku 'parrot', and some singulars end in consonants at least in surface form, e.g. mutum 'person', gabas 'east', so not even this general characterization holds.

In any case, there is an argument that shows specifically that Hausa singular nouns are indivisible, which forms the second part of the evidence against the Halle and Vergnaud analysis. Note first of all that there is a process of palatalization in Hausa such that coronal obstruents are manifested as alveopalatals when occurring before front vowels. Thus the coronals $s, t, d$, and $z$ become $S$ (orthographically $s h$ ), $\check{c}$ (orthographically $c$ ), $\breve{j}$ (orthographically $j$ ), and $\breve{j}$, respectively. Note the following examples:

(9)

yaa isa

yaa ishe ne

yaa saataa

yaa saacee shi

yaa saaci tuuluu

yaa gudu

a guje

yaa aagazaa

yaa aagajee shi

yaa aagaji mutum 'it is enough'

'it is enough for me'

'he stole (it)'

'he stole it'

'he stole the water pot'

'he ran away'

'on the run'

'he helped (someone)'

'he helped him'

'he helped the man' 
However, where borrowed vocabulary is concerned, the process frequently fails to apply within stems. Note the following examples:

\begin{tabular}{|c|c|c|}
\hline (10) & $\begin{array}{l}\text { tiitii } \\
\text { tiimaa } \\
\text { siisii } \\
\text { siiboo } \\
\text { ziinar̃ii } \\
\text { ziiyar̂tta } \\
\text { diihoo } \\
\text { diidamii }\end{array}$ & $\begin{array}{l}\text { 'street' } \\
\text { 'beat' } \\
\text { 'five-kobo coin' } \\
\text { 'theft' } \\
\text { 'gold' } \\
\text { 'to visit' } \\
\text { 'dampness' } \\
\text { 'leather apron' }\end{array}$ \\
\hline
\end{tabular}

What is of particular importance here is that in certain morphological contexts in which the result is a new, morphologically complex sequence of a coronal obstruent and a front vowel, the palatalization rule applies even to these borrowed forms (the examples in (9) above show the rule applying in derived forms in native vocabulary). For example, note the following:
(11)
tiitii
tiitoocii
'street/streets'
tikiti
tikitoocii
'ticket'

Plurals such as those in (11) are built on a pattern of partial reduplication which repeats the final consonant of the stem between the added vowels 00 and $i$; the following are further examples:
(12)

$\begin{array}{ll}\text { hanyaa } & \text { hanyooyii } \\ \text { teebur } & \text { teeburooorii }\end{array}$
'road/roads'
tambayaa
tambayooyii
'table/tables'
'question/questions'

What is of interest about the words in (11) is the fact that neither $t$ is palatalized in the singular form, and the first $t$ is not palatalized in the plural form, although the reduplicated $t$ is palatalized to an alveopalatal $c$ in the plural form where it occurs before the same ii vowel (there is of course some light phonetic palatalization of all instances of $t$ occurring before $i$, but it is not sufficient to produce the alveopalatal articulation characteristic of plural forms such as these). Thus, in spite of the fact that the environment is one of a high front vowel in each case, only in the plural form, between the suffixed vowels oo and ii, does the rule palatalizing coronals to alveopalatals apply.

A possible explanation for the forms in (11) is available in Lexical Phonology [Mohanan 1982, Pulleyblank 1984, Halle and Mohanan 1985]. As shown in (12), 
Hausa has a rule forming plurals of a certain class by partial reduplication. Further, there is a rule of palatalization of coronal obstruents to change them into alveopalatals before front vowels (the forms in the right-hand column in (11) are among those illustrating the effects of this process). However, this palatalization process applies only in derived environments, not within stems (the forms in (10) show that it does not apply within stems, and the plural form tiitoocii in (11) serves as an example of its application in a derived form). Thus, if the singular tiitii is interpreted as being an indivisible stem, the lack of palatalization of the second $t$ is accounted for in a manner parallel to that of the first $t-i$ it not in a derived form occurring before a front vowel. By contrast, the plural form can be understood as providing a new instance of a sequence of $t+i$ and thus as a derived form falling under the domain of the rule. Note that under the Halle and Vergnaud proposal there is no distinction between the singular and plural forms as regards their morphological structure, both being derived forms composed of a sequence of stem plus suffix, and thus the differing facts of palatalization in words like tiitii/tiitoocii cannot be explained with reference to this principle within their analysis.

It appears to be the case, then, that treatment of the final vowel in Hausa singular nouns as a separate morpheme has no justification and effects no economy.

Further, there is some evidence, though not common, which demonstrates that in fact the final vowel of the singular noun is not replaced by a plural suffix, as if the singular form were indeed a sequence of stem plus suffix, but that the plural suffix is added to the complete singular form itself (of course, in surface form the final vowel of the stem is in fact "replaced", but this is a result of a rule of vowel deletion, to be discussed below, not the result of morphological replacement). Note the following plural variants:

$\begin{array}{rll}\text { (13) bangoo } & \begin{array}{l}\text { bangaayee } \\ \text { bangwaayee } \\ \text { kangaayee } \\ \text { kangwaayee } \\ \text { kahoonii } \\ \text { kaho' }\end{array} & \text { 'wall' } \\ & \text { 'empty thing' } \\ & \text { 'hom' }\end{array}$

In these variant cases the nature of the final vowel of the singular form still shows its effects in the plural by labializing the final stem consonant. This is unexpected if the final vowel is a separate singular morpheme which is replaced in the plural by the plural morpheme, as the analysis of Halle and Vergnaud claims; rather, it is what would be expected if the plural suffix were simply added to a stem which already carried a round vowel, which in these instances is the full 
singular form itself. In particular, note that the variant forms can be easily accounted for in terms of a different ordering of the general rules of labialization (before round vowels) and vowel deletion (before following vowels):

$$
\text { bangoo + ayee bangoo+ aayee }
$$

Lab bangwoo+acyee V-Del bang + aayee

V-Del bangw + aayee

Lab

That is, if Vowel Deletion applies first, it bleeds away the form from possible application of the Labialization rule; if Labialization applies first, however, the rounded variant will appear, even though the following vowel in the surface form is not round.

Note that under the Halle and Vergnaud account the variant forms cannot be derived. Rather, under their approach the lexical form is not bangoo but bang-, and the oo which under this analysis is the singular marker attached by a morphological rule will not, of course, appear in the derivation of plural forms, leaving no possible source for the labialized variants. The only immediately apparent alternative is to treat the final stop of the stem in such cases as being already labialized in the lexicon in dialects using the rounded variants: bangw ${ }^{W_{-}}$. Such an analysis, however, would fail to recognize the fact that labialized consonants in Hausa (non-contrastive before round vowels and thus not written) are regularly the result of the influence of a following round vowel (e.g. the singular bangoo is pho-

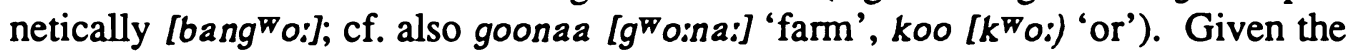
fact that there is an 00 in the singular forms in all of the words which manifest the variant labialized plural forms in (13), there is no reason to posit a lexical labialized stop, and in fact to do so would be misleading as to the source of the labialization.

Fortunately, it is not necessary to propose that Hausa singular nouns are formed by suffixation to demonstrate the usefulness of the notion of autosegmental tiers. Later in their 1981 paper Halle and Vergnaud discuss Luganda, using data (and basic analysis) from an unpublished paper by Clements. In this analysis syllables are analyzed hierarchically as being composed of onset (initial consonant) plus rime (everything else), with the rime having an internal structure of nucleus and optional appendix (coda). Typical syllable structure can thus be represented as follows: 
(15)

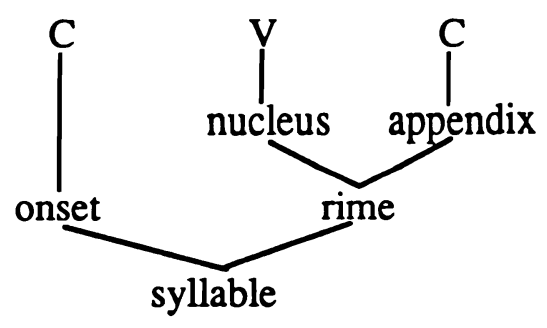

Given such an analysis it is demonstrated that Luganda has two rules of particular interest for the topic of this paper: (1) non-branching rimes (those with no appendix) become branching when they follow directly another rime; (2) in a sequence of consecutive rimes, all but the last is deleted. A sample derivation proceeds as follows:

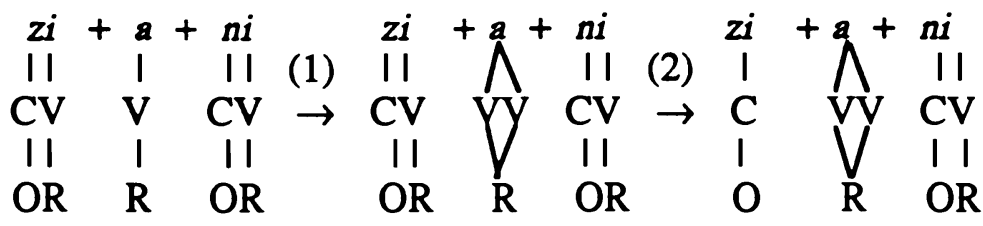

$$
\begin{aligned}
& z i+a+n i \quad z i+a i+n i \quad z+a i+n i
\end{aligned}
$$

In the last stage, because the $i$ has no association with any segment on the CV tier, it receives no phonetic expression. The result is the same as if the vowel were directly deleted by a rule:

\section{zaani}

'whose'

A related pattem is that in which some long high vowels become glides in stated contexts rather than being deleted:

(18) $1 i+$ ato lyato (no meaning given)

If such an analysis is proposed for Hausa plurals rather than treating the final vowel in the singular as a morpheme in its own right, a comparable pattern can be seen: 

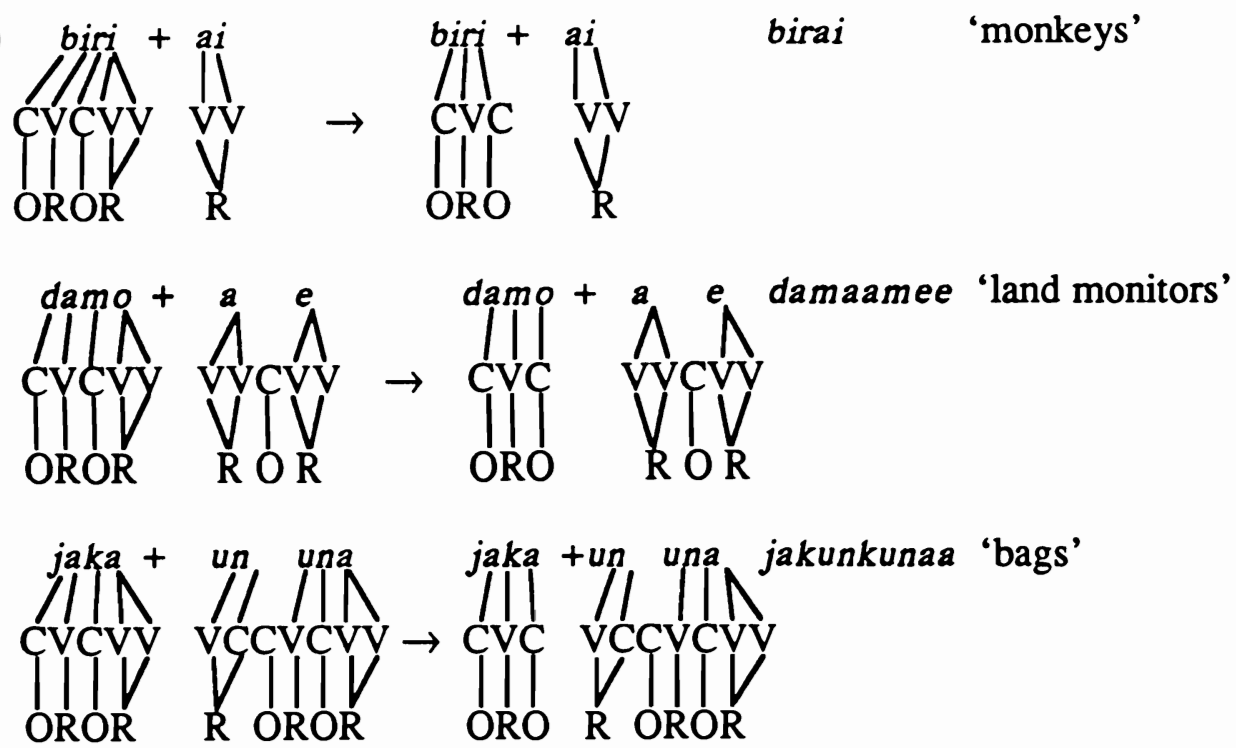

There is apparently no lengthening of rimes as in Luganda, but the deletion of all but the last of consecutive rimes appears to be the same. The precise nature of the suffixal consonant can be predicated to be either a copy of the final consonant of the stem or $y$ in the same way the variation is treated by Halle and Vergnaud. The two-dimensional nature of the display here prevents drawing the association line for the final consonant of the stem to the $C$ slot of the suffix, but this is an artifact of the formalism, not an inadequacy of the approach (see Pulleyblank [1984] for a suggestion that intersecting planes are a better representation of the tiers).

Under such an analysis the form of the plural must be stated lexically to the extent that it is not predictable, but there is no need to state a separate singular morpheme; the final vowel of the singular stem is simply its final stem vowel and therefore part of its lexical form. Further, as shown above, the dialect manifesting labialization in the plural forms in (13) can be accounted for by ordering application of the productive labialization rule in Hausa before the rule deleting the second rime in sequence. That is, the singular bangoo is always phonetically [bangwo:) because of the round vowel; the plural varies between [g] and [ $\left.g^{w}\right]$ dependent upon whether or not the round vowel is present at the time the labialization rule applies. In addition, the rime-deletion rule required by this proposal makes explicit the valid claim for Hausa that vowel sequences do not occur.

Note, however, that such a treatment forces a revision of the Halle and Vergnaud analysis in another way. Rather than treating ai and au in Hausa as simple vowel sequences as they have done, e.g. (1b), it is necessary to recognize that long vowels and these phonetic vowel combinations are in fact rimes compa- 
rable in structure. (This is not a new idea; it is alluded to at least as early as Leben [1977]). Rather than phonological sequences, such complex vocalic patterns are in fact units, so that a more suitable analysis of them is as follows:

(20)

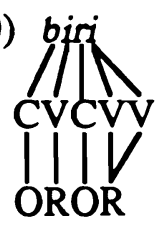

birii 'monkey'

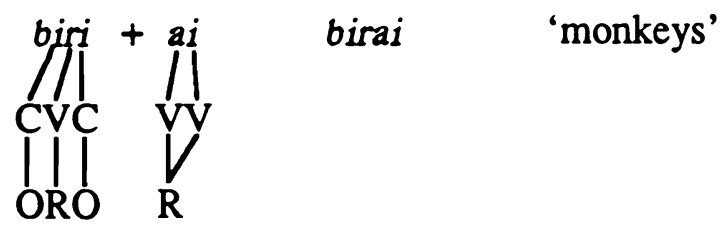

This is in fact the correct analysis; these are diphthongs, not sequences of vowels, and they manifest single rimes. Note that both long vowels and diphthongs in Hausa are subject to a totally general rule of shortening in closed syllables:

(21) gidaa

gidan mutum

kai 'compound'

'the compound of the man'

'head'

kan mutum

'the head of the man'

Thus an analysis that treats both long vowels and diphthongs in the same way (as manifesting single segments but corresponding to two positions in the CV tier) has justification. In fact, the rule to insert $y$ in those plural forms which do not copy the stem consonant can be interpreted as a strategy to prevent the rimes characterizing the plural vowels from coming together and thus causing one to be deleted. Because of its consonantal weakness and transitional nature, the glide $y$ is exactly the sort of segment we would expect to find in such contexts, especially before a front vowel. Further, the fact that in closed syllables both long vowels and diphthongs are comparably shortened shows that Hausa permits rimes with only a single appendix, which may be either length, the offglide of a diphthong, or a consonant. Thus there is a parallel between the deletion of a rime which directly precedes another rime and the deletion of an appendix which directly precedes another appendix: 

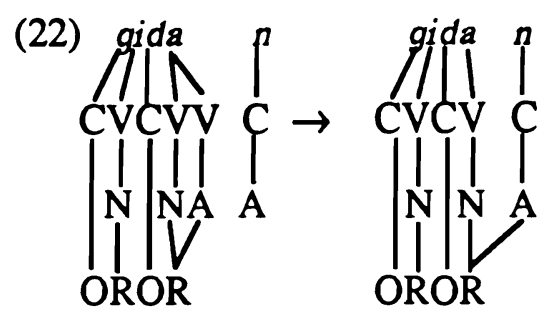

gidan

'compound of'

There are, however, some forms which threaten this analysis, which must be considered. First, note that there is at least one case in which the singular stem ends in 00 , but unlike the forms in (13), the plural shows no dialectal variation, occurring only in a labialized form:

\section{(23) angoo \\ angwaayee \\ 'bridegroom/bridegrooms'}

For this form, unlike the parallel bango/bangaayee/bangwaayee case, either the underlying representation contains a labialized consonant (unusual, given its predictable nature preceding a round vowel) or else (for this word and others like it) for all dialects the labialization applies before the round vowel is deleted. Thus at least two different sorts of patterns are found, even though the forms in question are parallel.

Further, note that the pattern of optional labialization is not paralleled by the palatalization cases. That is, where by a parallel argument we might expect the palatalized obstruents to occur by a variation in rule ordering, they do not:

\section{(24) fagee \\ fagaagee ${ }^{*}$ fagyaagee \\ 'field/fields'}

It is not clear why the two processes, parallel in many languages, are not parallel in Hausa. The explanation may be simply one of ordering, such that palatalization consistently follows vowel deletion and does not precede it, even in the dialect in question where labialization precedes vowel deletion. While this is perhaps less than ideal, there is no clear alternative analysis for the labialized variant above, so it has no direct bearing on the argument here.

Finally, note the following singular/plural pairs:

$\begin{array}{lll}\text { akushii } & \text { akusaa } & \text { 'black wooden bowl for food' } \\ \text { almakashii } & \text { almakasai } & \text { 'scissors' }\end{array}$

Here the singular forms end in ii, and the stem shows palatalization, as expected in native vocabulary. But the plural, having a vowel other than $i$, shows 
lack of palatalization. This could be taken as evidence that the stem in fact is consonant-final, and the final vowel of the singular form has a coronal obstruent, which becomes alveopalatal because (in this instance) a new occurrence of $s+i i$ is produced. Further, note the following, which shows dialectal variation also in the plural:
(26) ajii
ajuujuwaa/azuuzuwaa
'grade, class'

This form is troublesome because in the plural palatalization need not occur, there being no front vowel following. The variation can be explained on the same grounds as the bangoo case, but the difficulty here is that to use a parallel argument would necessitate positing a coronal obstruent which becomes alveopalatal, thus providing evidence for the Halle and Vergnaud claim that the singular form is a sequence of stem+affix. Further, Russ Schuh has pointed out to me parallel forms like the following:
(27) soojaa
soojoojii/soodoojii
'soldier/soldiers'
canjii
canzaa
'changing/to change'

In both of these instances the borrowed form has an alveopalatal obstruent, but at least a variant with a coronal obstruent when the $i$ conditioning environment is not present.

The solution may simply be that the palatalization rule in fact works both ways, to palatalize coronals before front vowels and to insure (in at least some dialects) that non-palatalized coronals occur before non-front vowels (I owe this suggestion to Bob Mugele). Such a rule can be formulated as follows:

(28) $\left[\begin{array}{c}- \text { son } \\ + \text { cor }\end{array}\right] \rightarrow[\alpha$ high $] /-\left[\begin{array}{c}+ \text { syll } \\ \alpha \text { back }\end{array}\right]$

If this rule is still considered to be a rule applying only to derived words, not to lexical stems, it can be expected to apply in all these cases mentioned here, but without contradicting the fact that in native vocabulary there are minimal contrasts between coronal and alveopalatal obstruents before non-front vowels. To the extent that soojoojii is a counterexample, it could be interpreted as analogically motivated, in that most such forms contain the same consonant in both positions in the plural (note the example in (26) and others in (12)). 


\section{REFERENCES}

Aronoff, M. 1976. Word Formation in Generative Grammar. Cambridge, MA: MIT.

Halle, M. \& K.P. Mohanan. 1985. "Segmental phonology of Modern English." Linguistic Inquiry 16:57-116.

Halle, M. \& J.-R. Vergnaud. 1980. “Three dimensional phonology.” Journal of Linguistic Research 1.1:83-105.

Halle, M. \& J.-R. Vergnaud. 1981. "Harmony processes." In W. Klein and W. Levelt (eds.), Crossing the Boundaries in Linguistics, pp. 1-22. Reidel, Dordrecht: Reidel.

Leben, W. 1977. "Length and syllable structure in Hausa." Studies in African Linguistics, Supplement 7, pp. 137-143.

McCarthy, J. 1979. "Formal problems in Semitic phonology and morphology." Doctoral dissertation, MIT.

McCarthy, J. 1981. "A prosodic theory of nonconcatenative morphology." Linguistic Inquiry 12:373-418.

Mohanan, K.P. 1982. “Lexical phonology." Doctoral dissertation, MIT.

Newman, Paul. 1972. "Syllable weight as a phonological variable." Studies in African Linguistics 3:301-323.

Pulleyblank, D. 1984. "Tone in lexical phonology." Doctoral dissertation, MIT. 